\title{
Research Paper: Effects of the Extremely Low Frequency Electromagnetic Fields on NMDA-Receptor Gene Expres- sion and Visual Working Memory in Male Rhesus Macaques
}

Masoomeh Kazemi ${ }^{1}$, Hedayat Sahraei ${ }^{1}$, Hamed Aliyari², Elaheh Tekieh ${ }^{1}$, Mehdi Saberi ${ }^{3}$, Hassan Tavacoli ${ }^{*}$, Gholam Hossein Meftahi ${ }^{1}$, Hossein Ghanaati $^{4}$, Maryam Salehi ${ }^{1}$, Mostafa Hajnasrollah ${ }^{5}$

1. Neuroscience Research Center, Baqiyatallah University of Medical Sciences, Tehran, Iran.

2. Faculty of Electrical, Biomedical and Mechatronics Engineering, Qazvin Branch, Islamic Azad University, Qazvin, Iran.

3. Department of Pharmacology, School of Medicine, Baqiyatallah University of Medical Sciences, Tehran, Iran.

4. Medical Imaging Centre, Imam Khomeini University Hospital, Tehran, Iran.

5. Reproductive Biomedicine Research Center, Royan Institute for Biotechnology, Academic Center for Education, Culture and Research (ACECR), Tehran, Iran.

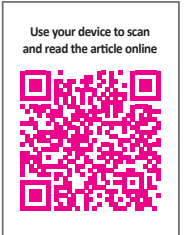

Citation: Kazemi, M., Sahraei, H., Aliyari, H., Tekieh, E., Saberi, M., Tavacoli, H., et al. (2018). Effects of the Extremely Low Frequency Electromagnetic Fields on NMDA-Receptor Gene Expression and Visual Working Memory in Male Rhesus Macaques. Basic and Clinical Neuroscience, 9(3), 167-176. https://doi.org/10.29252/NIRP.BCN.9.3.167

Funding: See Page 173

(c) Copyright: The Author(s)

Article info:

Received: 23 July 2017

First Revision: 31 July 2017

Accepted: 01 January 2018

Published: 01 May 2018

https://doi.org/10.29252/NIRP.BCN.9.3.167

Key Words:

ELF, Hippocampus, Melatonin, MRI, NMDA receptors, Visual working memory, Rhesus monkey

\begin{abstract}
A B S T RA C T
Introduction: The present research aimed to examine Visual Working Memory (VWM) test scores, as well as hormonal, genomic, and brain anatomic changes in the male rhesus macaques exposed to Extremely Low Frequency Magnetic Field (ELF-MF).

Methods: Four monkeys were exposed to two different ELF-MF frequencies: $1 \mathrm{~Hz}$ (control) and 12 $\mathrm{Hz}$ (experiment) with $0.7 \mu \mathrm{T}$ (magnitude) $4 \mathrm{~h} / \mathrm{d}$ for 30 consecutive days. Before and after the exposure, VWM test was conducted using a coated devise on a movable stand. About $10 \mathrm{~mL}$ of the animals' blood was obtained from their femoral vain and used to evaluate their melatonin concentration. Blood lymphocytes were used for assaying the expressions of N-Methyl-D-aspartate NMDA-receptor genes expression before and after ELF exposure. Anatomical changes of hippocampus size were also assessed using MRI images.

Results: Results indicated that VWM scores in primates exposed to $12 \mathrm{~Hz}$ frequency ELF increased significantly. Plasma melatonin level was also increased in these animals. However, these variables did not change in the animals exposed to $1 \mathrm{~Hz}$ ELF. At last, expression of the NMDA receptors increased at exposure to $12 \mathrm{~Hz}$ frequency. However, hippocampal volume did not increase significantly in the animals exposed to both frequencies.

Conclusion: In short, these results indicate that ELF $(12 \mathrm{~Hz})$ may have a beneficial value for memory enhancement (indicated by the increase in VWM scores). This may be due to an increase in plasma melatonin and or expression of NMDA glutamate receptors. However, direct involvement of the hippocampus in this process needs more research.
\end{abstract}




\section{Highlights}

- 12-Hz ELF exposure enhances the brain cognitive function.

- Brain cognitive function enhancement may be due to increase in plasma melatonin hormone and or increase in NMDA glutamate receptor gene expression.

\section{Plain Language Summary}

Extremely Low-Frequency Electromagnetic field is one of the most important factors affecting the environment. This study aimed to determine the effects of $12-\mathrm{Hz}$ frequency field on the visual changes of male monkeys. The research findings, because of the cognitive similarity of the monkeys to humans, can be generalized to humans. The results showed that the ELF/EMF increased the expression of the NMDA -R genes and melatonin hormone. They have two important roles in improving visual working memory. This study demonstrates the effect of the 12-Hz frequency on the monkey's visual memory. Researchers can use 12- Hz frequency on other cognitive indices. The test frequency may increase alpha brain waves $(12 \mathrm{~Hz})$, however, its confirmation requires more research.

\section{Introduction}

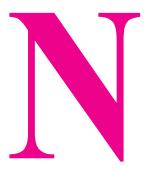

umerous studies have been carried out to reveal the biological, physiological, and behavioral effects of electromagnetic fields on humans and animal models. Given the biological similarities between monkeys and humans, more explicit and comprehensive studies have been carried out on the monkeys, especially Macaca mulatta species known as the rhesus macaque (De Lorge, \& Grissett, 1977; FabbriDestro \& Rizzolatti, 2008; Mitchell \& Leopold, 2015) which their genes have 98\% similarity with humans (Baharara \& Zahedifar, 2012; Fang et al., 2011; Kanthaswamy et al., 2013). Extremely Low Frequency (ELF) electromagnetic fields ranging from 1 to $300 \mathrm{~Hz}$ induce different effects on living organisms (Tekieh et al., 2017; Zhu et al., 2016). In this regard, researchers have examined the effect of electromagnetic fields on important biological processes such as cell proliferation, ion exchanges across the biological membranes, bone repair, nerve repair, production of free radicals, hormonal changes, enzyme activity modulation, and changes of membrane and intracellular proteins (Al-Akhras, Darmani, \& Elbetieha, 2006; Kula, Sobczak, \& Kuska, 2002; Marino \& Becker, 1977; Sobczak, Kula, \& Danch, 2002; Zare, Hayatgeibi, Alivandi, \& Ebadi, 2005). ELFs can affect the activity of brain neurons and thereby, interfere with brain waves as proved in extensive research on human and animal models. ELFs can reduce or increase the amplitude of different brain waves depending on their frequencies. Although, the magnitude and frequency of ELFs that decrease or increase the brain activity are not fully known, the organism's response depends on duration of exposure to the field and effects of previous fields. Thus, the sensitivity of humans to magnetic fields differs by person and requires extensive research (Cook, Thomas, \& Prato, 2002; Cvetkovic \& Cosic, 2009; Cvetkovic, Fang, \& Cosic, 2008).

On the other hand, different types of memories are part of the important functions of the nervous system. They are severely influenced by environmental factors and are able to change the mental state. Of these mental states, stress and anxiety can impair brain memory function (McEwen, Nasca, \& Gray, 2015; Rostami et al., 2016). Psychologists and neurologists believe that hippocampus plays a key role in the formation of new memories of observed events (Richter-Levin \& Akirav, 2000; Shahrivar, Moazedi, Rasekh, Almasi-Turk, \& Roozbehi, 2014). Interestingly, ELFs can interact with the hippocampal neurons' activity which may interfere with the ability of hippocampus for memory storage (Alkadhi, 2013; Rostami et al., 2016). This effect may be due to activation of stress system and possibly other hormones, which in fact shrinks the hippocampus size. In addition, increase in hippocampal glutamate system activity is shown to be involved in memory storage and therefore some investigators propose that stress hormones released during stressful events may induce glutamate system hyperactivity and reduce the cell size and connections within the hippocampus (Lucassen et al., 2014; McEwen et al., 2015; Tekieh et al., 2017)

The present research objective was to examine the effects of ELF with $1 \mathrm{~Hz}$ (as control group) and $12 \mathrm{~Hz}$ (as experimental group) frequencies with a magnitude of $0.7 \mu \mathrm{T}$ on the cognitive, morphological, and hormonal changes in the rhesus macaque monkeys. For this purpose, Visual Working Memory (VWM), RMI images 
of the hippocampus, plasma level of melatonin and expression of glutamate N-Methyl-D-Aspartate (NMDA) receptor were evaluated in these animals. Melatonin (N-acetyl-5-methoxy tryptamine) is a hormone secreted from pineal gland and contributes to modulation of the sleep-wake cycle (the circadian rhythm). The short-term effects of melatonin variations may affect decision-making, memory, and learning in humans (Fukunaga, Horikawa, Shibata, Takeuchi, \& Miyamoto, 2002; Ozdemir et al., 2005; Touitou \& Selmaoui, 2012).

\section{Methods}

\subsection{Animals}

Four adult male rhesus macaques (Macaca mulatta), 4-5 years old with an average weight of $4 \mathrm{~kg}$ were used for this study. In this research, two monkeys were placed in the 12-Hz electromagnetic field (experimental group) and two others monkeys at $1-\mathrm{Hz}$ electromagnetic field (control group). The animals received all needed vaccines (Hepatitis-B, HIV, and herpes). The monkeys were kept at the animal room laboratory of Neuroscience Research Center, Baqiyatallah University of Medical Sciences for 150 days for adaptation. The animals were kept in 12:12 hours dark/light cycle at room temperature $\left(24^{\circ} \mathrm{C} \pm 2^{\circ} \mathrm{C}\right.$ ) with adequate food and water (mal at 8,12 , and $16 \mathrm{O}$ 'clock and water was provided with scaled water nipples co ntainer in $1000 \mathrm{~mL}$ volume specifically designed for monkeys). All of the experiments were conducted according to the Baqyiatallah Medical University Medical Ethics Committee (No. 112-1394).

\subsection{ELF exposure procedure}

The ELF equipment can generate different frequencies from 1 to $300 \mathrm{~Hz}$, made by Dr. Jafargholi laboratory, Amir Kabir University of Technology, Tehran, Iran. This generator can produce a magnetic field with the magnitude of $0.7 \mu \mathrm{T}$ in $160-\mathrm{cm}$ diameter circle field. The ELF exposure was conducted for each primate as follows: each primate was transferred to the shielded room in a $1 \times 1 \times 1 \mathrm{~m}$ Teflon cage. The cage was put $50 \mathrm{~cm}$ away from the ELF equipment and the wave generator became ON. The exposure was lasted $4 \mathrm{~h} / \mathrm{d}$ for each animal.

\subsection{Visual Working Memory Test}

A VWM device (hidden behind a curtain) was designed for this test. The device included two opaque dishes (each dish with a window opening in one direction and rewards invisible to the primates). The two coated dishes were on a movable stand (Cook et al., 2002; Richter-
Levin \& Akirav, 2000). The animals were tested after 17 hours of fasting. The primates were transferred to the behavioral test room separately, and the test was carried out in two phases.

\subsubsection{Cognitive Behavior Test}

The VWM device was placed in front of the cage and the primate's favorite reward (peanut) was shown to it which was randomly placed in one of the dishes. The curtain was drawn so that the animal cannot watch the dishes for 30 seconds. After this time, the curtain was removed and the dishes was presented to the animal on a movable stand. Each animal was allowed to make only one attempt to pick the reward from one of the two dishes. In other words, the animal had to remember the dish with the reward, and if the animal opened the wrong container, it would be deprived of the reward. This test was carried out three times a day for 30 days.

\subsubsection{Second experiment phase}

The VWM test was administered with a minor difference. The time of curtain covering was doubled (60 seconds instead of 30 seconds). Then, the dish was presented to the animal. This test was also repeated 3 times a day (Constantinidis \& Procyk, 2004).

\subsection{MRI imaging}

Animals were fasting for $9 \mathrm{~h}$ and then anesthetized using ketamine hydrochloride $(10 \mathrm{mg} / \mathrm{kg})$. A $3 \mathrm{~T} \mathrm{MRI}$ device in the T1 and T2 phases with 3-mm sections of the axial, sagittal, and coronal regions (for better anatomic interpretation of the regions of concern). In the image interpretation phase, volumetric assessments of hippocampus were analyzed in Image $\mathrm{J}$ (Jaba, Shanthi, Singh, 2011).

\subsection{Hormonal assays}

The primates were put in the stabilized state of consciousness and $10 \mathrm{~mL}$ of blood was obtained from their femoral vain (popliteal artery) for determination of melatonin content. The blood samples were divided into two parts. The first part was centrifuged at $3000 \mathrm{rpm}$ for 5 minutes at a temperature of $4^{\circ} \mathrm{C}$ and the serum content was isolated for melatonin measurement using melatonin ELISA kit (MyBioSource, USA).

\subsection{Assays of NMDA receptors gene expression}

The second part of the blood samples was used for cellular and molecular assays. After collecting the blood 
samples, its lymphocytes were isolated using the Ficoll solution in a centrifuge at $1500 \mathrm{rpm}$ in for 5 minutes followed by another 15 minutes at $2500 \mathrm{rpm}$. The isolated lymphocytes were tested to determine expression of NMDA receptor genes using the PCR technique. To assess the impact of the ELF exposure on the expression of NAMD receptor gene, the semi-quantitative reverse transcriptase-polymerase chain reaction (semi-RT-PCR) was utilized. As described earlier, peripheral blood sample was collected from each animal in related time and the total mRNA was purified by the RNX-Plus kit (CinnaGen, Iran) in accordance with the manufacturer's guideline. The quantity and quality of each isolated RNA was evaluated using the NanoDrop spectrophotometer (Thermos, USA) and agarose gel electrophoresis, respectively. After that, to synthesize cDNA from each sample, Bioneer kit (Takara, Japan) was applied. Briefly, 100 ng of each RNA sample was converted to cDNA by the Master Mix containing M-MLV Reverse Transcriptase, random hexamers, oligo (dT) and related buffer. Finally, the NAMD2A gene expression was detected using PCR and related specific primer set. The mRNA expression of $\beta$-actin was assessed as an internal control. All PCR reactions were performed in a thermal cycler (Techne, UK) containing $1.5 \mu \mathrm{L}$ cDNA, $0.2 \mathrm{mM}$ of the deoxyribonucleoside triphosphates (dNTPs), $2.5 \mathrm{mM} \mathrm{MgCl}, 10 \mathrm{pmol}$ of each primers and 1.5 U of Taq DNA Polymerase (CinnaGen, Iran). PCR program consisted of $6 \mathrm{~min}$ initial denaturation at $94^{\circ} \mathrm{C}, 35$ cycles of $45 \mathrm{~s}$ at $95^{\circ} \mathrm{C}, 45 \mathrm{~s}$ at $58^{\circ} \mathrm{C}$ for NMDA and $\beta$-actin and $56^{\circ} \mathrm{C}$ for NMDA $2 \mathrm{~A}$ and $1 \mathrm{~min}$ at $72^{\circ} \mathrm{C}$ followed by $7 \mathrm{~min}$ final extension at $72^{\circ} \mathrm{C}$. To measure the density of amplicons, each PCR product was run on $2 \%$ agarose gel electrophoresis, stained by ethidium bromide and visualized under UV gel document. Finally, the density of each product band was measured by Image
J (Hillmann, Ramdas, Multanen, Norman, \& Harmon, 2000; Mahmoodzadeh Hosseini, Soleimanirad, Mehdizadeh Aghdam, Amin, \& Fooladi, 2015).

\subsection{Analysis method}

The study method is descriptive because the number of samples was low. Two types of comparisons were made in this study. First, the monkeys were compared with themselves (before and after radiation). That is, monkeys exposed to $12 \mathrm{~Hz}$ and monkeys exposed to $1 \mathrm{~Hz}$ ELF. Second, because monkeys exposed to $1 \mathrm{~Hz}$ did not show much changes they were introduced as the control group and compared with monkeys exposed to $12 \mathrm{~Hz}$ as the experimental group.

\section{Results}

Results show the percentage of correct answers of VWM test of the primates after radiation with ELF waves. It revealed that in the B-F (the experiment) monkeys (exposed to the $0.7 \mu \mathrm{T}$ field at $12 \mathrm{~Hz}$ ), VWM scores (with a hidden reward) changed considerably following the radiation. However, in the D-E monkeys, which was exposed to the $0.7 \mu \mathrm{T}$ field at $1 \mathrm{~Hz}$ (control group), VWM did not change considerably (Figure 1) (Table 1).

Results of anatomical assays (MRI) at 12 and $1 \mathrm{~Hz}$ (The wavelength of $1 \mathrm{~Hz}$ was used as control) frequencies using the $0.7 \mu \mathrm{T}$ field did not reveal significant changes in volumetric properties of the left hippocampus in the coronal or axial section (Figures 2, 3) (Table 2).

Plasma melatonin increased following the radiation of the $12 \mathrm{~Hz}$ wave with $0.7 \mu \mathrm{T}$ field magnitude in the ex-

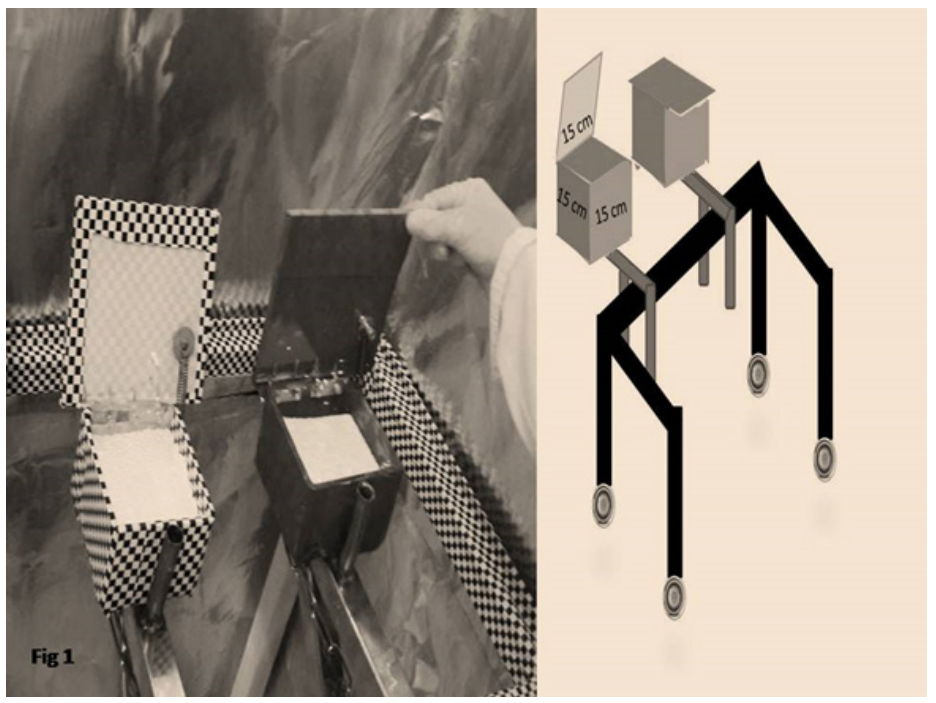

Figure 1. Plexiglass coated dishes (containing invisible reward) 
Table 1. The percentages of correct answers of VWM before and after irradiation in the monkeys*

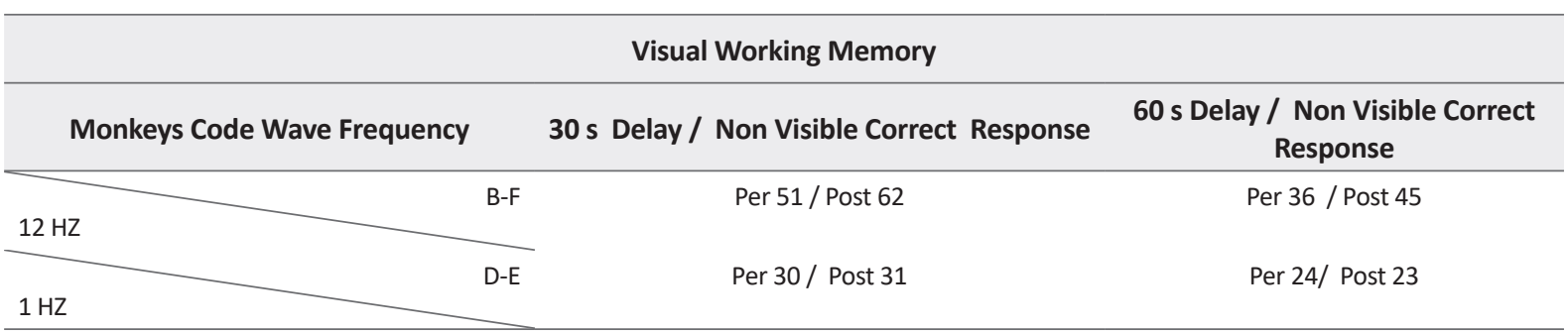

NEUR:SCIENCE

*Visual working memory decreased significantly in the 30- and 60-second periods as compared to the pre-radiation state.

perimental primates and remained unchanged under the impact of the $1 \mathrm{~Hz}$ radiation in the control group. The recovery of both primates involved restoration of their states to the pre-radiation phase (Figure 4).

Effects of radiation with the $12 \mathrm{~Hz}$ and $1 \mathrm{~Hz}$ frequencies ( $1 \mathrm{~Hz}$ frequency was used as control) with $0.7 \mu \mathrm{T}$ field on expression of the NMDA receptor in the control and experiment primates showed that changes of expression of the NMDA gene under the impact of the $12 \mathrm{~Hz}$ wave and the $0.7 \mu \mathrm{T}$ field increased significantly in the experimental primates following radiation. However, expression of NMDA gene under the impact of the $1 \mathrm{~Hz}$ wave and $0.7 \mu \mathrm{T}$ fields changes slightly in the control group following radiation. The recovery of both primates involved restoration of their states to the preradiation phase (Figure 5).

\section{Discussion}

Our experiments indicate that exposure to the lowfrequency $(12 \mathrm{~Hz})$ electromagnetic wave with $0.7 \mu \mathrm{T}$

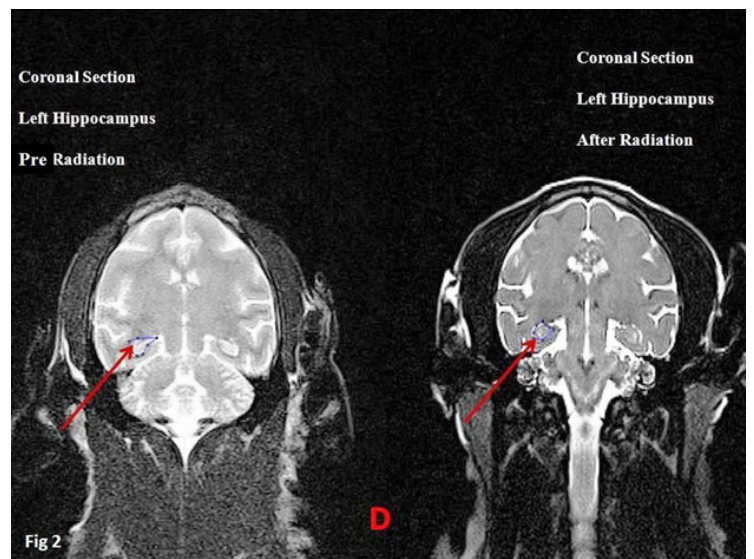

NEUR SCIENCE

Figure 2. Volumetric analysis of the left hippocampus of primates (D-B)

Arrows show the hippocampus. magnetic field magnitude may have a significant effect on cognitive functions changes, as shown in VWM decline in primates. Besides this memory decline, results showed a decrease in plasma melatonin concentration and an increase in NMDA receptor gene expression. These results may reveal hazardous features of ELF on living organisms, especially the primates.

Previous studies indicate that the ELF effect can be various with respect to the wave frequencies and the radiation period as well as biological and physiological properties of humans and animals (Ross et al., 2015; Salford \& Nittby, 2012). In this regard, it is shown that magnetic field with a frequency of $50 \mathrm{~Hz}$ impair memory and learning in human (Sakhnini et al., 2014; Salford \& Nittby, 2012). Results of the other researchers have also revealed that ELF waves with 10 and $30 \mathrm{~Hz}$ frequencies and field magnitude of $2 \mu \mathrm{T}$ improves memory and learning in rats (An et al., 2015; Casile, 2013; D’Angelo, Costantini, Kamal, \& Reale, 2015; Rimbach et al., 2014; Sakhnini et al., 2014).

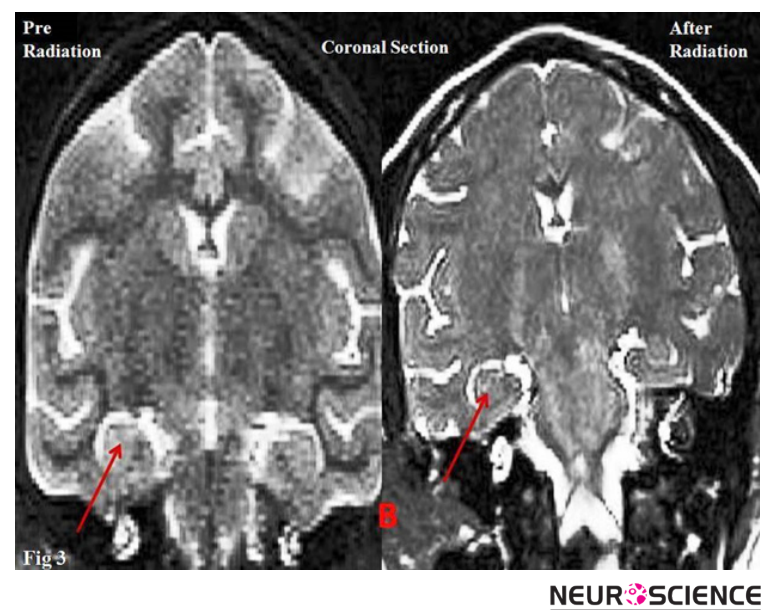

Figure 3. Volumetric analysis of the left hippocampus of primates (D-B)

Arrows show the hippocampus. 
Table 2. Changes in the volume of the left hippocampus after radiation with $1 \mathrm{~Hz}(\mathrm{D}-\mathrm{E})$ and $12 \mathrm{~Hz}(\mathrm{~B}-\mathrm{F})$

\begin{tabular}{|c|c|c|c|}
\hline Monkey & Codes & $\begin{array}{c}\text { Coronal Section Left Hippocampus Volume }(\mathrm{mm}) 3 \\
\text { Pre-radiation }\end{array}$ & $\begin{array}{l}\text { Coronal Section Left Hippocampus Volume } \\
\qquad(\mathrm{mm}) 3 \text { Post-radiation }\end{array}$ \\
\hline B-F & $12 \mathrm{HZ}$ & 293.9 & 316.2 \\
\hline D-E & $1 \mathrm{HZ}$ & 345.225 & 353.345 \\
\hline
\end{tabular}

No significant difference was observed.

NEUR \$SCIENCE

Working memory is an important and fundamental cognitive process that forms the basis of thinking and learning also it is associated with storage and processing of information in the mind. Results of cognitive tests show the percentage of correct answers significantly increased after irradiation with $12 \mathrm{~Hz}$ frequency both at 30 s and $60 \mathrm{~s}$ schedules.

In addition, as shown in Table 1, the VWM test scores were particularly enhanced in the animals exposed to the $12-\mathrm{Hz}$ ELF, therefore the exposure may be strong enough to interact with the areas of the animals' brains that increase their memory capacity. We hold that this enhancement may occur in the hippocampus as it is shown in several animal and human studies (Keller \& Roberts, 2009; Jaba, Shanthi, \& Singh, 2011; Tae et al., 2008; Tekieh et al., 2017). However, it is interesting that our results in MRI studies did not support our hypothesis. To date, there is no discussion about this phenomenon but one may conclude that the effects of the 12-Hz ELF exposure may affect other brain areas. This idea must be studied in the future research.

In another part of the present study, the effect of $12-\mathrm{Hz}$ ELF exposure was examined on the melatonin hormone. Melatonin is considered as the sleep and wake hormone released from pineal gland during dark period (Baydas et al., 2005; D'Angelo et al., 2015; Pandiperumal et al., 2008). Our data indicate that melatonin plasma con-

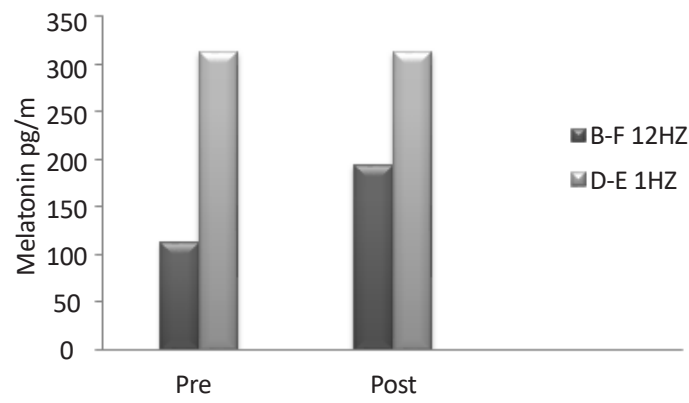

NEUR:SCIENCE

Figure 4. N-methyl-D-aspartate receptor gene expression in the $1 \mathrm{~Hz}$ (D-E) and $12 \mathrm{~Hz}$ (B-F) wavelengths exposed animals

The expression of these receptors' gene was higher in the 12 $\mathrm{Hz}$ exposed animals than the control animals. centration is elevated after $12-\mathrm{Hz}$ ELF exposure. The increased plasma melatonin level may be responsible for the increased animals' VWM scores. In this regard, several studies support that melatonin can increase brain cognitive function via increase in the beta wave in EEG (Baharara \& Zahedifar, 2012; Baydas et al., 2005; Hampton et al., 2005; Lingnau, Gesierich, \& Caramazza, 2009). However, it is too soon to draw conclusion about the hormonal effect on VWM.

The hippocampus-subiculum path is important in learning, memory process; also Long-Term Potentiation (LTP) mechanism is important for the formation of some forms of memory and learning. In the visual cortex, the LongTerm Depression (LTD) and LTP points display many mechanisms with synaptic plasticity that associate with the sense of sight. LTP is related with the visual cortex that is dependent on the NMDA receptor channels with their significant role in learning and memory (Lynch, 2004; Morris, 2013; Nakazawa, McHugh, Wilson, \& Tonegawa, 2004; Newcomer, Farber, \& Olney, 2000).

Finally, our result indicate that N-Methyl-D-Aspartate glutamate receptors (NMDA) gene expression was elevated after 12-Hz ELF exposure. This finding may indicate that by an unknown mechanism(s), ELF can increase the gene expression as indicated by the increment in the gene expression in our study. This part

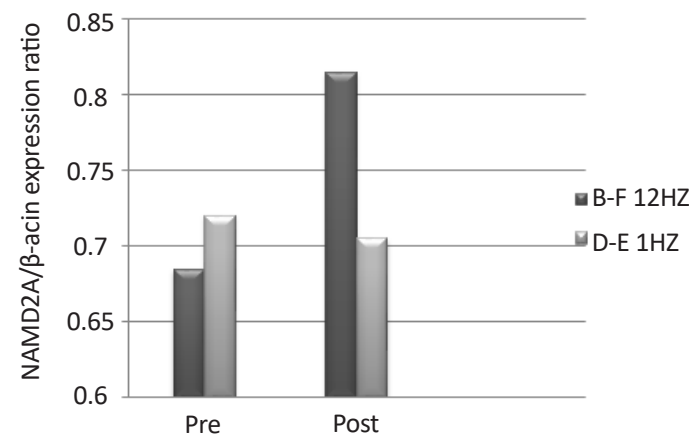

NEUR:SCIENCE

Figure 5. N-Methyl-D-Aspartate receptor gene expression in the $1 \mathrm{HZ}(\mathrm{D}-\mathrm{E})$ and $12 \mathrm{HZ}(\mathrm{B}-\mathrm{F})$ wavelengths exposed animals The expression of these receptors' gene was higher in the 12 $\mathrm{HZ}$ animals than the control animals. 
of the study may also support the VWM high scores in these animals as well.

In conclusion, 12-Hz ELF exposure enhances the brain cognitive function in the rhesus monkeys as indicated by the increase in VWM test scores. This improvement may be due to increase in plasma melatonin hormone and or increase in NMDA glutamate receptor gene expression. However, the potential clinical use of these findings would be a suitable topic for the future experiments.

\section{Ethical Considerations}

\section{Compliance with ethical guideline}

All of the experiments were conducted according to the Baqyiatallah Medical University Medical Ethics Committee (No. 112-1394).

\section{Funding}

This research was financially supported by Neuroscience Research Center, Baqiyatallah Medical Science University.

\section{Conflict of interest}

All authors have no potential conflict of interest pertaining to this journal submission.

\section{Acknowledgments}

Hereby we would like to extend our earnest gratitude to their efforts and cooperation. We also highly appreciate the assistance of Asab Fanavari Pars Company.

\section{References}

Al-Akhras, M. A., Darmani, H., \& Elbetieha, A. (2006). Influence of $50 \mathrm{~Hz}$ magnetic field on sex hormones and other fertility parameters of adult male rats. Bioelectromagnetics, 27(2), 127-131. [DOI:10.1002/bem.20186]

Alkadhi, K. (2013). Brain Physiology and Pathophysiology in Mental Stress. ISRN Physiology, 2013, 1-23. [DOI:10.1155/2013/806104]

An, G. Z., Xu, H., Zhou, Y., Du, L., Miao, X., Jiang, D. P., et al. (2015). Effects of Long-Term 50Hz Power-Line Frequency Electromagnetic Field on Cell Behavior in Balb/c 3T3 Cells. PLOS ONE, 10(2), e0117672. [DOI:10.1371/journal.pone.0117672]

Baharara. J., Zahedifar, Z. (2015). The effect of low-frequency electromagnetic fields on some biological activities of animals. Arak Medical University Journal, 15(7), 80-93.
Baydas, G., Özer, M., Yasar, A., Tuzcu, M., \& Koz, S. T. (2005) Melatonin improves learning and memory performances impaired by hyperhomocysteinemia in rats. Brain Research 1046(1-2), 187-194. [DOI:10.1016/j.brainres.2005.04.011]

Casile, A. (2013). Mirror neurons (and beyond) in the macaque brain: An overview of 20 years of research. Neuroscience Letters, 540, 3-14. [DOI:10.1016/j.neulet.2012.11.003]

Constantinidis, C., \& Procyk, E. (2004). The primate working memory networks. Cognitive, Affective, E Behavioral Neuroscience, 4(4), 444-465. [DOI:10.3758/CABN.4.4.444]

Cook, C. M., Thomas, A. W., \& Prato, F. S. (2002). Human electrophysiological and cognitive effects of exposure to ELF magnetic and ELF modulated RF and microwave fields: A review of recent studies. Bioelectromagnetics, 23(2), 144-157. [DOI:10.1002/bem.107]

Cvetkovic, D., \& Cosic, I. (2009). Alterations of human electroencephalographic activity caused by multiple extremely low frequency magnetic field exposures. Medical \& Biological Engineering \& Computing, 47(10), 1063-1073. [DOI:10.1007/s11517009-0525-1

Cvetkovic, D., Fang, Q., \& Cosic, I. (2008). Multiple human electrophysiological responses to extremely low-frequency pulsed electromagnetic field exposures: a pilot study. Estonian Journal of Engineering 14(2), 138-153. [DOI:10.3176/eng.2008.2.04]

D’Angelo, C., Costantini, E., Kamal, M. A., \& Reale, M. (2015) Experimental model for ELF-EMF exposure: Concern for human health. Saudi Journal of Biological Sciences, 22(1), 75-84. [DOI:10.1016/j.sjbs.2014.07.006]

De Lorge, J. O., \& Grissett, J. D. (1977). Behavioral effects in monkeys exposed to extremely low frequency electromagnetic fields. International Journal of Biometeorology, 21(4), 357-365. [DOI:10.1007/BF01555197]

Fabbri-Destro, M., \& Rizzolatti, G. (2008). Mirror Neurons and Mirror Systems in Monkeys and Humans. Physiology, 23(3), 171-179. [DOI:10.1152/physiol.00004.2008]

Fang, X., Zhang, Y., Zhang, R., Yang, L., Li, M., Ye, K., et al (2011). Genome sequence and global sequence variation map with 5.5 million SNPs in Chinese rhesus macaque. Genome Biology, 12(7), R63. [DOI:10.1186/gb-2011-12-7-r63]

Fukunaga, K., Horikawa, K., Shibata, S., Takeuchi, Y., \& Miyamoto, E. (2002). Ca2+/calmodulin-dependent protein kinase II-dependent long-term potentiation in the rat suprachiasmatic nucleus and its inhibition by melatonin. Journal of Neuroscience Research, 70(6), 799-807. [DOI:10.1002/jnr.10400]

Hampton, R. R., Hampstead, B. M., \& Murray, E. A. (2005) Rhesus monkeys (Macaca mulatta) demonstrate robust memory for what and where, but not when, in an openfield test of memory. Learning and Motivation, 36(2), 245-259. [DOI:10.1016/j.lmot.2005.02.004]

Hillmann, A. G., Ramdas, J., Multanen, K., Norman, M. R., \& Harmon, J. M. (2000). Glucocorticoid receptor gene mutations in leukemic cells acquired in vitro and in vivo. Cancer Research 60(7), 2056-62. [PMID]

Jaba, L., Shanthi, V., \& Singh, D. (2011). Estimation of Hippocampus Volume from MRI Using ImageJ for Alzheimer's Diagnosis. Atlas Journal of Medical and Biological Sciences, 15-20. [DOI:10.5147/ajmbs.2011.0045] 
Kanthaswamy, S., Ng, J., Ross, C. T., Trask, J. S., Smith, D. G., Buffalo, V. S., et al. (2013). Identifying human-rhesus macaque gene orthologs using heterospecific SNP probes. Genomics, 101(1), 30-37. [DOI:10.1016/j.ygeno.2012.09.001]

Keller, S. S., \& Roberts, N. (2009). Measurement of brain volume using MRI: software, techniques, choices and prerequisites. Journal of Anthropological Sciences. 87, 127-151. [PMID]

Kula, B., Sobczak, A., \& Kuska, R. (2002). Effects of Electromagnetic Field on Free-Radical Processes in Steelworkers. Part I: Magnetic Field Influence on the Antioxidant Activity in Red Blood Cells and Plasma. Journal of Occupational Health, 44(4), 226-229. [DOI:10.1539/joh.44.226]

Lingnau, A., Gesierich, B., \& Caramazza, A. (2009). Asymmetric fMRI adaptation reveals no evidence for mirror neurons in humans. Proceedings of the National Academy of Sciences, 106(24) 9925-9930. [DOI:10.1073/pnas.0902262106]

Lucassen, P. J., Pruessner, J., Sousa, N., Almeida, O. F. X., Van Dam, A. M., Rajkowska, G., et al. (2013). Neuropathology of stress. Acta Neuropathologica, 127(1), 109-135. [DOI:10.1007/ s00401-013-1223-5]

Lynch, M. (2004). Long-Term Potentiation and Memory. Physiological Reviews, 84(1), 87-136. [DOI:10.1152/physs rev.00014.2003]

Mahmoodzadeh Hosseini, H. M., Soleimanirad, J., Mehdizadeh Aghdam, E. M., Amin, M., \& Fooladi, A. A. (2015). Texosomeanchored superantigen triggers apoptosis in original ovarian cancer cells. Medical Oncology, 32(1), 409. [DOI:10.1007/ s12032-014-0409-6]

Marino, A. A., \& Becker, R. O. (1977). Biological effects of extremely low-frequency electric and magnetic fields: a review. Physiological Chemistry and Physics, 9(2), 131-147. [PMID]

McEwen, B. S., Nasca, C., \& Gray, J. D. (2015). Stress Effects on Neuronal Structure: Hippocampus, Amygdala and Prefrontal Cortex. Neuropsychopharmacology, 41(1), 3-23. [DOI:10.1038/ npp.2015.171]

Mitchell, J. F., \& Leopold, D. A. (2015). The marmoset monkey as a model for visual neuroscience. Neuroscience Research, 93, 20-46. [DOI:10.1016/j.neures.2015.01.008]

Morris, R. G. M. (2013). NMDA receptors and memory encoding. Neuropharmacology, 74, 32-40. [DOI:10.1016/j.neuropp harm.2013.04.014]

Nakazawa, K., McHugh, T. J., Wilson, M. A., \& Tonegawa, S. (2004). NMDA receptors, place cells and hippocampal spatial memory. Nature Reviews Neuroscience, 5(5), 361-372. [DOI:10.1038/nrn1385]

Newcomer, J. W., Farber, N. B., \& Olney, J. W. (2000). NMDA receptor function, memory, and brain aging. Dialogues in Clinical Neuroscience, 2(3), 219-32. [PMID] [PMCID]

Ozdemir, D., Tugyan, K., Uysal, N., Sonmez, U., Sonmez, A., Acikgoz, O., et al. (2005). Protective effect of melatonin against head trauma-induced hippocampal damage and spatial memory deficits in immature rats. Neuroscience Letters, 385(3), 234-239. [DOI:10.1016/j.neulet.2005.05.055]

Pandiperumal, S. R., Trakht, I., Srinivasan, V., Spence, D. W., Maestroni, G. J., Zisapel, N., et al. (2008). Physiological effects of melatonin: Role of melatonin receptors and signal trans- duction pathways. Progress in Neurobiology, 85(3), 335-353. [DOI:10.1016/j.pneurobio.2008.04.001]

Richter-Levin, G., \& Akirav, I. (2000). Amygdala-Hippocampus Dynamic Interaction in Relation to Memory. Molecular Neurobiology, 22(1-3), 11-20. [DOI:10.1385/MN:22:1-3:011]

Rimbach, R., Link, A., Montes-Rojas, A., Di Fiore, A., Heistermann, M., \& Heymann, E. W. (2014). Behavioral and physiological responses to fruit availability of spider monkeys ranging in a small forest fragment. American Journal of Primatology, 76(11), 1049-1061. [DOI:10.1002/ajp.22292]

Ross, C. L., Siriwardane, M., Almeida-Porada, G., Porada, C. D., Brink, P., Christ, G. J., \& Harrison, B. S. (2015). The effect of low-frequency electromagnetic field on human bone marrow stem/progenitor cell differentiation. Stem Cell Research, 15(1), 96-108. [DOI:10.1016/j.scr.2015.04.009]

Rostami, A., Shahani, M., Zarrindast, M. R., Semnanian, S., Rahmati Roudsari, M., Rezaei Tavirani, M., \& Hasanzadeh, H. (2016). Effects of $3 \mathrm{~Hz}$ and $60 \mathrm{~Hz}$ Extremely Low Frequency Electromagnetic Fields on Anxiety-Like Behaviors, Memory Retention of Passive Avoidance and Electrophysiological Properties of Male Rats. Journal of Lasers in Medical Sciences, 7(2), 120-125. [DOI:10.15171/jlms.2016.20]

Sakhnini, L., Al-Ghareeb, S., Khalil, S., Ahmed, R., Ameer, A. A. \& Kamal, A. (2014). Effects of exposure to $50 \mathrm{~Hz}$ electromagnetic fields on Morris water-maze performance of prenatal and neonatal mice. Journal of the Association of Arab Universities for Basic and Applied Sciences, 15(1), 1-5. [DOI:10.1016/j. jaubas.2013.05.004]

Salford, L. G., \& Nittby, H. (2012). Effects of Electromagnetic Fields From Wireless Communication upon the Blood-Brain Barrier. Paper presented in: BioInitiative Working Group: "A Rationale for Biologically-Based Exposure Standards for Low-Intensity Electromagnetic Radiation. Amsterdam: Bioinitiative.

Shahrivar, T., Moazedi, A. A., Rasekh, A. R., Almasi-Turk, S., \& Roozbehi, A. (2014). [The effects of intrahippocampus injection of progesterone on passive avoidance learning and memory in adult male rats (Persian)]. Iranian South Medical Journal, $17(4), 524-532$.

Sobczak, A., Kula, B., \& Danch, A. (2002). Effects of Electromagnetic Field on Free-Radical Processes in Steelworkers. Part II: Magnetic Field Influence on Vitamin A, E and Selenium Concentrations in Plasma. Journal of Occupational Health, 44(4), 230-233. [DOI:10.1539/joh.44.230]

Tae, W. S., Kim, S. S., Lee, K. U., Nam, E. C., \& Kim, K. W (2008). Validation of hippocampal volumes measured using a manual method and two automated methods (FreeSurfer and IBASPM) in chronic major depressive disorder. Neuroradiology, 50(7), 569-581. [DOI:10.1007/s00234-008-0383-9]

Tekieh, E., Riahi, E., Kazemi, M., Sahraei, H., Tavakoli, H., Aliyary, H., et al. (2017). Role of basal stress hormones and amygdala dimensions in stress coping strategies of male rhesus monkeys in response to a hazard-reward conflict. Iranian Journal of Basic Medical Sciences 20(8), 951-957. doi: 10.22038/ ijbms.2017.9120

Touitou, Y., \& Selmaoui, B. (2012). The effects of extremely lowfrequency magnetic fields on melatonin and cortisol, two marker rhythms of the circadian system. Dialogues in Clinical Neuroscience, 14(4), 381-399. [PMID] [PMCID] 
Zare, S., Hayatgeibi, H., Alivandi, S., \& Ebadi, A. (2005). Effects of Whole-body Magnetic Field on Changes of Glucose and Cortisol Hormone in Guinea Pigs. American Journal of Biochemistry and Biotechnology, 1(4), 217-219. [DOI:10.3844/ ajbbsp.2005.217.219]

Zhu, K., Lv, Y., Cheng, Q., Hua, J., \& Zeng, Q. (2016). Extremely low frequency magnetic fields do not induce DNA damage in human lens epithelial cells in vitro. The Anatomical Record, 299(5), 688-697. [DOI:10.1002/ar.23312] 
